\title{
DESCRIPTION OF THE FRICTIONAL GEARING USED ON A DOUBLE STEAM DREDGER IN THE PORT OF DUBLIN.
}

By Mr. JOHN PURSER GRIFFITH, Pregident of the Institution of Civil Engineers of Ireland.

The double Steam Dredger No. 4 in the Port of Dublin was built by Messrs. Thomas Wingate and Co. of Glasgow in 1871, and at that date was one of the largest dredgers afloat. Both sets of dredge buckets, the hoisting gear for the ladder, and the fore and aft winches are all worked by a single-cylinder low-pressure condensing side-lever engine of 150 indicated horse-power. It will be readily understood how necessary it is to be able at will to disconnect the gearing of either set of buckets from the main engine, or to raise the bucket ladders and warp the dredger about without driving the upper tumblers.

Grooved Gearing.-To meet these requirements the builders. adopted Robertson's grooved frictional gearing (Proceedings 1856, page 202), as shown in Figs. 1, 2, and 3, Plates 69 to 71 . Two. grooved pinions $\mathrm{P}$ of 54 inches diameter, with nine grooves cut to an angle of $40^{\circ}$ and $1 \frac{3}{4}$ inch pitch, were fixed on the engine shaft $E$, and geared into two grooved wheels $W$ of $127 \frac{1}{2}$ inches diameter, running on intermediate shafts $S$ but not keyed to them. Each of these wheels revolved on an eccentric gun-metal bush $\mathrm{B}$, embracing the intermediate shaft and turning freely on it; and by means of long levers $\mathrm{L}$ connected with the eccentric bushes the grooved wheels could be put in and out of gear with the pinions on the engine shaft. A cast-iron driver $D$ kejed on the intermediate shaft was connected with the grooved wheel by a pin and sliding guide-block $G$, in such a manner as to allow of the eccentric motion; so that. when the grooved wheel was thrown into gear it carried the cast-iron 
driver round with it, and thereby turned the intermediate shaft $S$, on which was keyed a toothed pinion $\mathrm{N}$ gearing into the large spurwheel $U$ of the upper tumbler. Thus at will either or both upper tumblers could be put in and out of gear without stopping the engine. The speed of the grooved wheels at their circumferences was about 500 feet per minute. If half the engine power were transmitted by each set of gearing, and allowance be made for the friction of the engine itself, the tangential force at the rims would be about 3,960 lbs.; requiring, if the angle of the grooves were $40^{\circ}$ and the coefficient of friction $0 \cdot 18$, a pressure of 7,524 lbs. between wheel and pinion to prevent slipping.

The dredger began dredging in Dublin in 1872, and worked on the average forty-seven weeks per annum for eleven years till 1883, when it was sunk by collision, having raised nearly 4,500,000 tons. The large friction wheels $W$ were practically worn out, and the pinions $P$ had been twice renewed and also re-turned, at a cost of nearly $£ 300$. A renewal of the rims of the large wheels, which were separate castings from the bosses and arms, would have cost at least £200. The life of the pinions may be taken as five years, and of the wheels twelve years; and these relative durations are found to be nearly proportional to the circumferences of tho pinions and wheels. The cost of repairs and renewals of the grooved gearing, if the wheel rims had been renewed, would therefore have averaged about $£ 47$ per annum, or $£ 1$ per working week.

Some of the difficulties experienced in connection with this grooved gearing arose from variations in the hardness of the castings. Soft spots wore faster than the hard portions; and by degrees there was a tendency to slip at the soft spots, unless the wheels were kept in gear by very considerable pressure. As the large wheels wore down, the rim deflected between the arms; and this also caused unequal wear, which was attended by slipping of the gearing. In No. 4 dredger the pinion $P$ was wider in the face than the large wheel $W$ into which it geared, and was placed below it, as shown in Plate 70. The oil from the upper bearings trickled down the large wheel, and labricated the outer grooves of the pinion. The wear and tear of these outer grooves was therefore less than of the intermediate 
grooves. This led to their having a greater share of the pressure than the central grooves, and resulted in the outer faces bursting off.

In addition to the mere angle, the form of the groove is an important feature in grooved gearing. When wheels of unequal diameters work into each other, it must be borne in mind that the small wheel will wear faster than the large; and the shape of the grooves in both wheels should be such that they will remain similar in shape till the tops of the ridges begin to touch the bottoms of the grooves, Fig. 4, Plate 71. As soon as this point is reached, the wheels must of course be re-turned or renewed. The practice of cutting the ribs with a uniform slope down to the bottoms of the grooves is objectionable, for, as the npper portions of the ribs wear, shoulders are formed in the sides, as shown in the section, Fig. 3, Plate 71 ; and on these shoulders the ends of the ribs of the adjoining wheel begin to bear, instead of on the sloping surfaces. Increased pressure has to be applied to keep the wheels in gear, and the advantages of the grooving are lost.

In 1885 and 1886, after the dredger had been raised and repaired, it was worked for a short time with the same frictional gear; but the large wheels were so worn that their rims cracked in several places between the arms. After carefully considering the question of renewal, it was decided by Mr. Bindon B. Stoney, the Chief Engineer of the Dublin Port and Docks Board, to adopt the arrangement shown in Figs. 5, 6, and 7, Plates 71 to 73.

Spur Gearing with Bralee-Wheels.-In place of the grooved pinion and wheel, a toothed pinion $P$ is keyed on the engine shaft $E$, gearing into a spur-wheel $W$ which runs loose on the intermediate shaft $\mathbf{S}$; and to the side of the spur-wheel is bolted a cast-iron brakewheel $\mathrm{K}$. As in the original arrangement, a cast-iron driver $D$ is keyed on the intermediate shaft. At each end of the driver is hinged a $T$ shaped lever T, Fig. 5. To the short arms of the lever are attached with adjusting screws two steel brake-bands $B$, the other ends of which are fastened in a similar manner to the corresponding $T$ lever at the opposite end of the driver. The steel bands $B$ thus embrace the brake-wheel $\mathrm{K}$ like a brake-strap. The long arms of the 
$T$ levers are connected by tension rods $R$ with bell-cranks $J$ hinged at the centre of the driver; and the bell-cranks are also connected with a collar $\mathrm{C}$ sliding on the intermediate shaft and revolving with the driver. The collar can be moved backwards or forwards along the shaft by a long lever $L$ worked by a hand-wheel and screw $H$, so as to loosen or tighten the steel bands on the brake-wheel. When the engine is working, the large spur-wheel $\mathrm{W}$ and its attached brake-wheel $\mathrm{K}$ revolve; and by tightening the steel bands till they grip the brake-wheel, the driver and intermediate shaft $S$ are set in motion, together with the upper tumbler and its chain of dredge buckets.

The diameter of each brake-wheel is 88 inches, its breadtb 6 inches, and the speed at its circumference about 400 feet per minute. In regular work the steel brake-bands are supposed to transmit half the engine power. Each set of gear however is designed of sufficient strength to transmit the maximum power which the engine can exert: that is, on the supposition that the engine may be pulled up at half stroke with the full steam-pressure and vacuum on the piston, and with only one set of friction gear in operation. In practice the brakes slip before any such stress is reached, as they are only tightened sufficiently to start the drivers and buckets.

The whole apparatus is simple and effective. Its wearing parts are accessible and easily renewed at small cost. Engineers having charge of machinery naturally take special interest in the cost of maintenance, which is sometimes overlooked by designers and manufacturers. The importance of reducing wear and tear in dredging machinery will, it is thought, sufficiently justify the foregoing description of a detail which occupies a prominent position in the working of dredgers. 


\section{Discussion.}

The Prasident said this practical paper, giving the result of Mr. Griffth's experience in the working of dredgers over many years, was of a kind which the Institution always welcomed, because such experience as the author had gained and had here placed before the Members could not fail to be valuable to mechanical engineers in general, whether directly concerned with dredgers or not. It showed that the question of cost in frictional gearing was very much a question of durability of surfaces, and that their durability was in proportion to the circumferences of the grooved wheels which geared together.

Mr. Bindon B. SToney said the number of buckets that could be raised per minute with the original grooved frictional gear had been twelve: with the modified brake gear the number was fourteen, with a rather less consumption of coal. This of course was a great advantage, as it increased the efficiency of the dredger by one-sixth. A further objection to the grooved frictional gear, in addition to those which had been mentioned in the paper, was that, when it got out of order and the rubbing parts were much worn, it required a great deal of effort to put it in and out of gear, and the act of doing so was attended with more or less risk to the engine-driver; in fact, one of the men operating on it got one of his hands rather severely injured, and that had been a principal reason for considering how the method of driving could be improved. Another advantage of the present mode of driving was that it acted perfectly as a friction brake, in case the dredger came against some obstacle which made it desirable to pull up the engine gradually rather than have something give way. On such occasions the brakes slipped a little; and being put in and out of gear several times every day, they were invariably in good working order. The ordinary arrangement of safety brake which was used in dredging machinery, as most engineers were probably aware, consisted of brass blocks forced by screws into contact with the circumference of a drum. These frequently were not slipping 
(Mr. Bindon B. Stoney.)

for weeks or months together; and the result was, according to his experience, that they invariably got locked, and ceased to act at the critical moment. The friction brake now described could not get out of order, and this constituted an additional advantage in its favour. The effort to put it in and out of gear was so slight that a child could do it. It generally took three or four seconds to put it into gear, and rather less to put it out.

Mr. Danizl Adamson, Vice-President, had read the paper with a view to its being communicated to the Institution, and had concluded that, although it was not a long one, it was thoroughly practical and valuable, because as an engineer the author had confessed his troubles and made known the failure of frictional gear. Frictional gear when at its best was properly so named, because it then was truly a method of gearing by means of friction. But where the frictional surfaces passed through only 500 feet per minute, or say 8 feet per second, the plan was utterly inapplicable, because it could never be satisfactorily adapted to such a slow motion. If locomotive driving wheels had to run at the same low rate, very little work would be got out of the engine. In the present case, if the frictional surfaces had run ten times as fast, with the loads correspondingly reduced to one-tenth, the wheels would have had all the adhesion wanted, and would have lasted a great deal longer than it was possible for them to do with slow and heary loads. A further practical lesson taught by the paper was in regard to the want of uniformity of metals, and also how they suffered when subjected to compression beyond a certain point. The larger grooved wheel $\mathrm{W}$ shown in Fig. 1, Plate 69, would no doubt have been much more durable if there had been double the number of spokes for giving greater support to its circumference. Whilst congratulating the author on having removed the frictional gear and substituted spur gear, he would point out that, with the large experience of spur gear which most engineers had in Lancashire, they would not think of running such wheels under 30 feet per second, instead of only about 400 feet per minute or say 7 feet per second. This slower speed however when using spur gear was merely a question of 
strength. If the slow speed was the object that had to be attained, the strength of the wheels must be made commensurate with that slow rate. But if it was required to utilise the full power of a spur wheel, and to get such a duty from it as was consistent with its diameter and pitch, then certainly instead of running in practical work at only 7 feet per second it would be wiser to run up to at least 30 feet per second. Lighter wheels could then be used for running at the higher speeds, while at the same time they would be much more durable. The substitution of the brake for the common frictional clutch he thought was wise; it was a change from a small surface to a large one, and the employment of a large drum altogether encircled by a brake-strap was to his mind the perfection of the method of getting friction and letting go, without great stress or wear and tear. For his own part he was especially thankful to anyone who had the courage to confess that things had not done as well as they ought to have done, and that substitutions had been made which had always done better. There were two lessons to be learnt in all such cases: something to avoid, and something to imitate. In the present instance the thing to be aroided was the use of frictional gear with a slow speed, and a heary load of more than 3 tons in order to produce friction enough to prevent slipping. The thing to be imitated was the better plan of employing spur gear for the purpose intended.

The use of helical teeth for the geared wheels he considered would be advantageous in the present instance, as in many other cases; and his own experience was that the helical teeth were growing rapidly into favour for all practical purposes, because they gave a screw motion. In a planing machine, for instance, instead of having the tooth-marks right across the work, as was the case with straight spur gearing, wheels with helical teeth took hold and let go over a larger extent of their circumference, and the result was a smooth surface with no tooth-marks on it. The helical teeth had also the advantage of increased strength, and an increased extent of surface to resist wear and tear. From his own experience in their use he believed that under a heavy load the driving pressure on the teeth of the pinion or smaller wheel ought to be arranged to come 
(Mr. Daniel Adamson.)

on their convex face, because the pinions necessarily wore faster than the larger wheels with which they geared; and therefore, instead of the tendency being to pull the pinion teeth out, as would be the case if the pressure came on their concave surface, it was desirable that the contact should be on their outer or convex surface, in order that they might be under compression in working. He had known a case latterly where a pinion working under a heavy pressure had had to be changed, the teeth having suffered so much from the contact on their concave faces. Since the change had been made, so that the pressure now came on the convex surface of its teeth, the pinion had worked with great satisfaction, and there had been no trouble at all.

Mr. Jeremina Head, Past-President, had had some exporience with frictional gearing of almost identically the same form as that shown in Fig. 2, Plate 70, but used for a different purpose. Sixteen years ago Mr. B. L. Lauth of Pittsburg, America, had introduced into this country three-high rolls for rolling plates; * and he had himself put down a mill on that plan, the middle roll being smaller in diameter than the other two. As the bottom roll only was driven, it was believed that, when the plate came back between the top roll and the middle roll in its return pass, it would slip and stand still, if it had to be driven entirely through the friction of the middle and bottom rolls. Consequently a cage of threehigh grooved friction pinions, of the eame diameter as the plate rolls and almost as long, was put at the end of the train, and coupled to the plate rolls as regarded the top and bottom rolls, the grooves in the friction pinions being just like those shown in Fig. 3, Plate 71. The plan seemed to work well at first; but in a short time the grooves were found to wear precisely as had been described, first of all by making shoulders on their sides, and then by the points of the ridges bottoming in the bottoms of the grooves; then they had to be taken out and re-turned. But while they were wearing, it was necessary to screw the tightening screws down tight, in order to get the requisite friction; and this was found to be so much against the

* Journal of the Iron and Steel Institute, 1872, rol. 2, pagcs 86 and 353. 
engine that it took almost as much power to drive the pinions as the plate rolls when in action. Eventually a trial was made of doing away with the grooved gearing and running the mill without it; and it was found that when the gearing was discontinued the difficulty which had been anticipated did not really exist: the rolls were driven perfectly well without any gearing at all. It was desirable however to reduce the plates more in the roughing rolls, so that by the time they entered the finishing rolls they were tolerably thin and not too hot.

Mr. John A. F. Aspinall had had some experience of grooved friction wheels for driving a saw for cutting steel ingots, and in that case the frictional gearing gave a great deal of trouble: it was always wearing down exactly in the way described by the author, and ultimately the engine and all the gear connected with it were taken away, and replaced by an arrangement for driving tho saw direct. In another case, where the grooved gear was used for a crane, it had little work upon it, being used only occasionally, and it there did very well. For work of that kind, which was light and only occasional, the grooved gearing was perhaps a handy form of mechanism; but the surface contact was so small that, if any hard work was put upon it, it simply wore out too rapidly to warrant its being continued.

Mr. Grirtitr had been specially interested in the remarks of Mr. Adamson and Mr. Head, and their experience seemed to bear out in every particular the views he held himself. Mr. Adamson had pointed out that grooved frictional gearing might be suitable for high speeds and low pressures, but was unsuited for such low speeds and high pressures as wete mentioned in the paper. From all he had read about the grooved gearing, he thought it only just to Mr. Robertson, the inventor, to say that all the evidence seemed to show he had originally intended it only for high speeds and low pressures. It was now sixteen years since this dredger began work, and it might perhaps have been thought that the grooved gearing had now become obsolete for such a purpose; but this was not the 
(Mr. Griffith.)

case, for the new large dredger for Swansea, recently illustrated in “ Engineering" (13 July 1888, page 45), was fitted with grooved gearing apparently identical with that described in the paper.*

Upon the estimate given in the paper of 7,524 lbs. as the pressure between wheel and pinion necessary to transmit a tangential force of 3,960 lbs. at the rims, he had expected some criticism, because this pressure was much greater than the advocates of frictional grooved gearing would probably allow. At the time when his gearing was first introduced, Mr. Robertson himself had claimed a tangential or driving adhesion amounting to one and a half times the radial pressure holding the wheels in contact: in which case the pressure in the present instance need only have been 2,640 lbs., instead of 7,524 lbs. No qualification had been made by Mr. Robertson for the angle of the grooves, and in his original paper read to this Institution (Proceedings 1856 page 202) the above proportion seemed to be associated with an angle of about $50^{\circ}$ : while Professor Rankine in his "Applied Mechanics" (1858 page 618), when referring to these results, had associated them with an angle of $40^{\circ}$, adding however the explanation that "this proportion is much greater than that due to ordinary friction, and must arise partly from adhesion." From some experiments carried out in Dublin on the friction of grooved surfaces he himself believed that the assertion that grooved gearing was capable of transmitting a tangential force of $1 \frac{1}{2}$ times the radial pressure could not be sustained as a general claim for all angles. On purely mechanical principles $T=\mu P \operatorname{cosec} \frac{\theta}{2}$; where $T=$ tangential force transmitted, $\mu=$ coefficient of friction, $P=$ radial pressure keeping the wheels in contact, and $\theta=$ angle of the grooves. If it were the case that in grooved gearing $T=1 \frac{1}{2} P$, irrespective of the angle of the grooves, the extraordinary conclusion would be arrived at

* Since the Meeting the author has been informed by Messrs. Fleming and Ferguson of Paisley, the builders of the Swansea dredger, that they had to supply the grooved gearing because it was specified, but that all their experience is against the use of this gear for main drivers, and they themselves would never adopt it or recommend its adoption. They find that frictional gearing answers well for other purposcs, such as hoisting \&e.; but where it has been tried for the main gearing it has given more or less trouble. 
that the coefficient of friction varied with the angle. For Mr. Robertson's frictional clutches however the angle generally used was $14^{\circ}$; and it seemed not improbable that the results which were now associated with grooved gearing generally had originally been obtained from grooves cut to the angle of $14^{\circ}$. This presumption was supported by the fact that on taking $\mu=0.18$ and $\theta=14^{\circ}$ the above equation would give $T=1 \frac{1}{2} P$; and it was still further supported by Mr. Robertson's statement (Proceedings 1856 page 209) that the adhesion with his grooved gearing was about nine times that with plain surfaces, which would theoretically be true for an angle of about $13^{\circ}$. If this were the case, it would readily be understood how the grooved gearing had been used in the dredger under conditions which must inevitably lead to failure.

A saving in coal consumption had been mentioned by Mr. Stoney as having been effected by the change of gear. From a careful examination it had been found that the dredger was now using 17 tons of corl per working week, while the average of the eleven years with the grooved gearing had been 19 tons. The saving therefore of 2 tons per working week, equivalent to $24 s$, might he thought be fairly credited to the change; and this seemed to be confirmed by Mr. Head's remark about the three-high rolls with grooved frictional gearing, that it took almost as much power to drive the friction pinions as the plate rolls when in action. Making also the very liberal allowance of 2s. per week for renewals of straps, brake wheels, and friction rings, instead of the $£ 1$ per week previously expended, the alteration of this one detail had resulted in a saving of about $\$ 100$ per annum, while at the same time, as pointed out by Mr. Stoney, the efficiency of the dredger had been increased about one-sixth or 16 per cent.

The President was sure the Members would wish to offer their best thanks to Mr. Griffith for his valuable paper, showing so clearly what might be used under the circumstances described, and what ought to be aroided. 


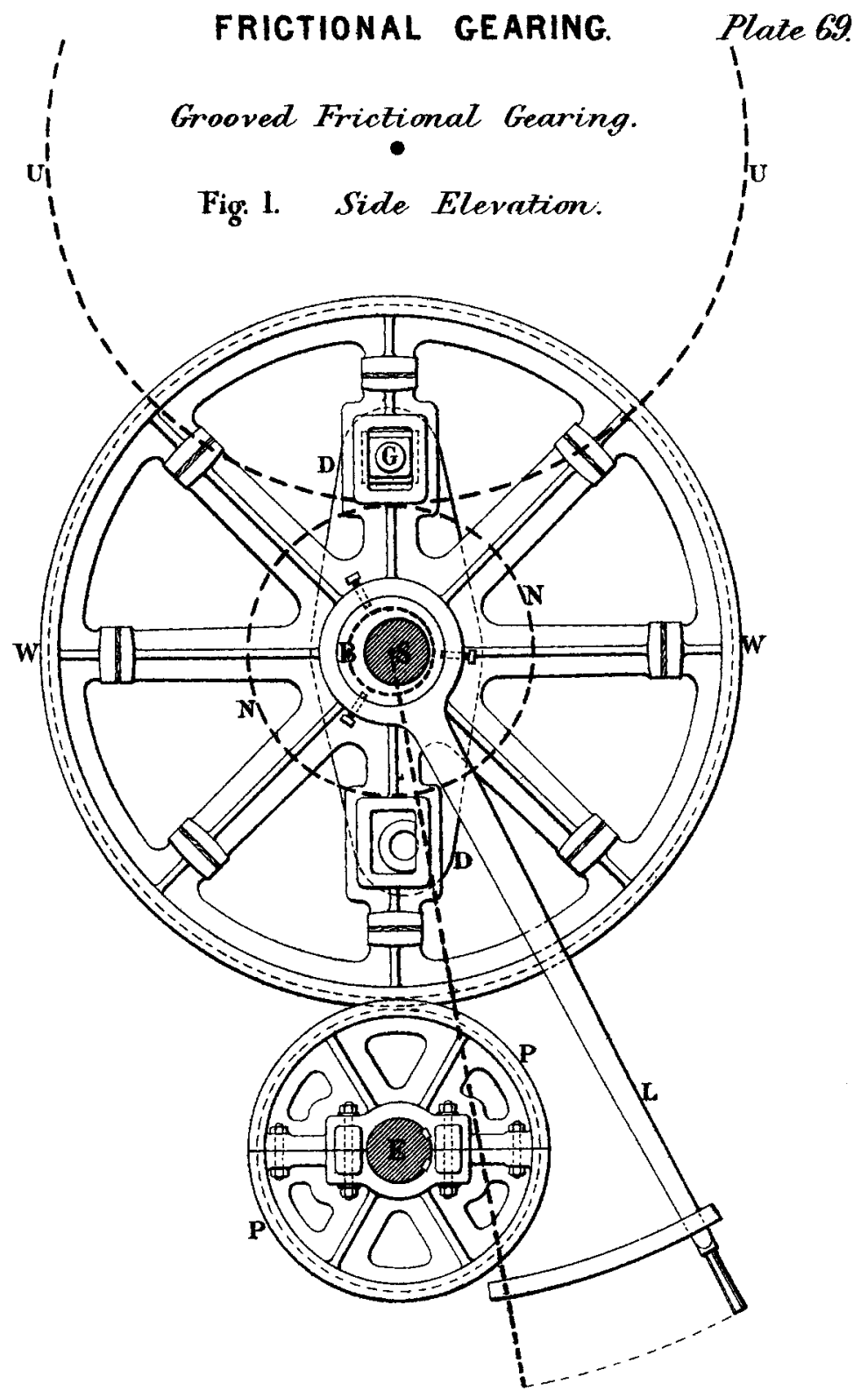

(Proceedings Trust. M. E. 1888./

Scale $1 / 40^{\text {th }}$ Frohes 12 \begin{tabular}{lllllllllll}
6 & 0 & 1 & 2 & 3 & 4 & 5 & 6 & 7 & 8 & 9 \\
\hline
\end{tabular} 


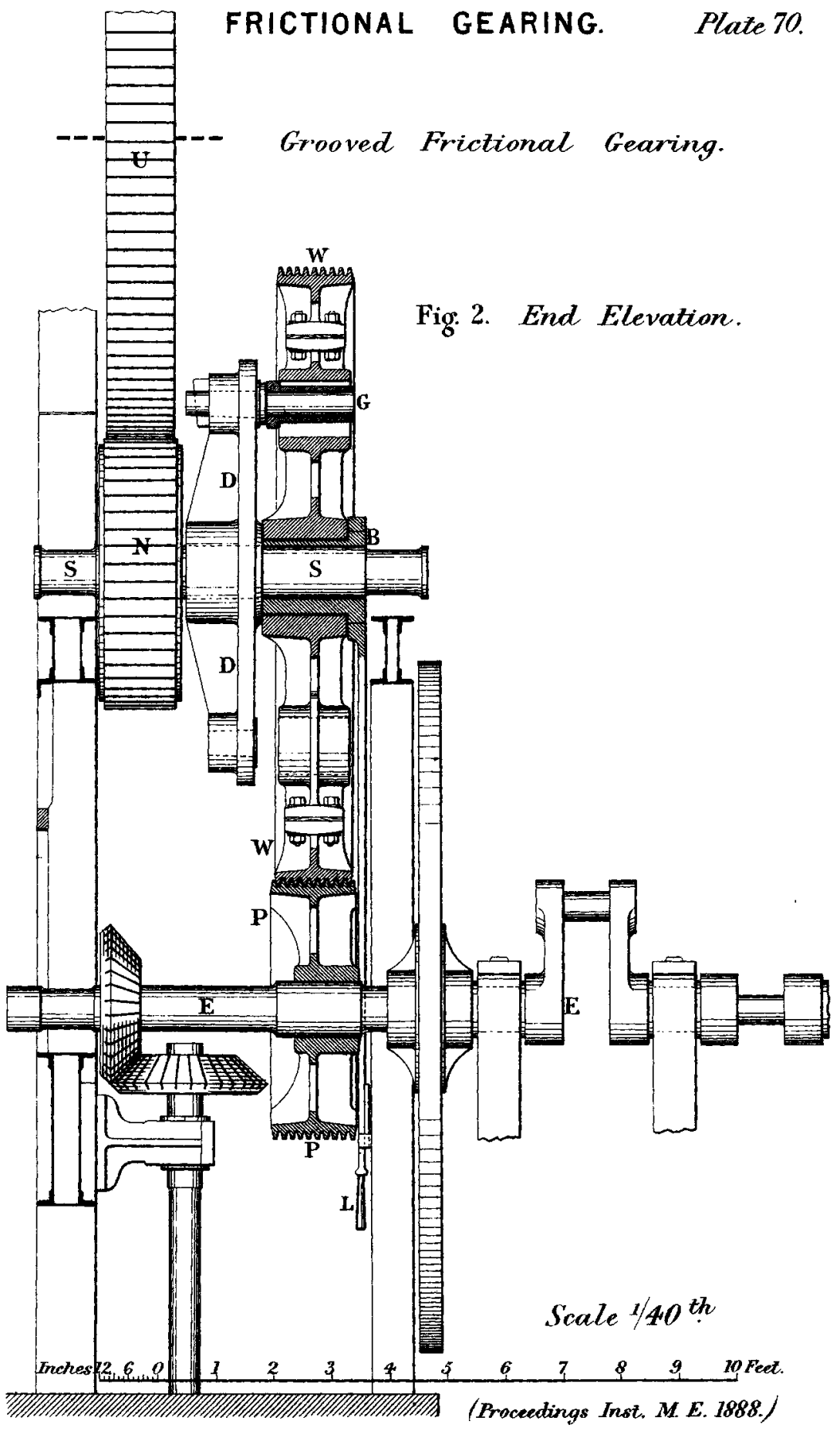


FRICTIONAL GEARING.

Plate 7l.

Grooved Frictional Gearing.

Fig: 3. Grooves when worn. Scale $1 / 4^{\text {th }}$
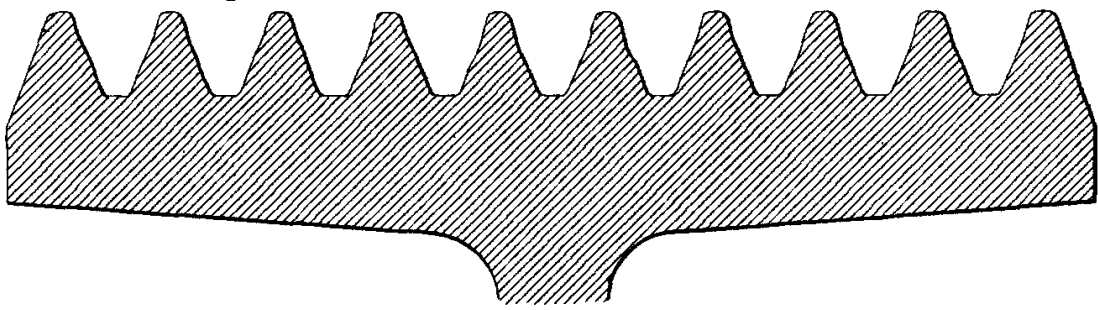

Fig. 4. New form of Grooves. Scale $1 / 4$ th
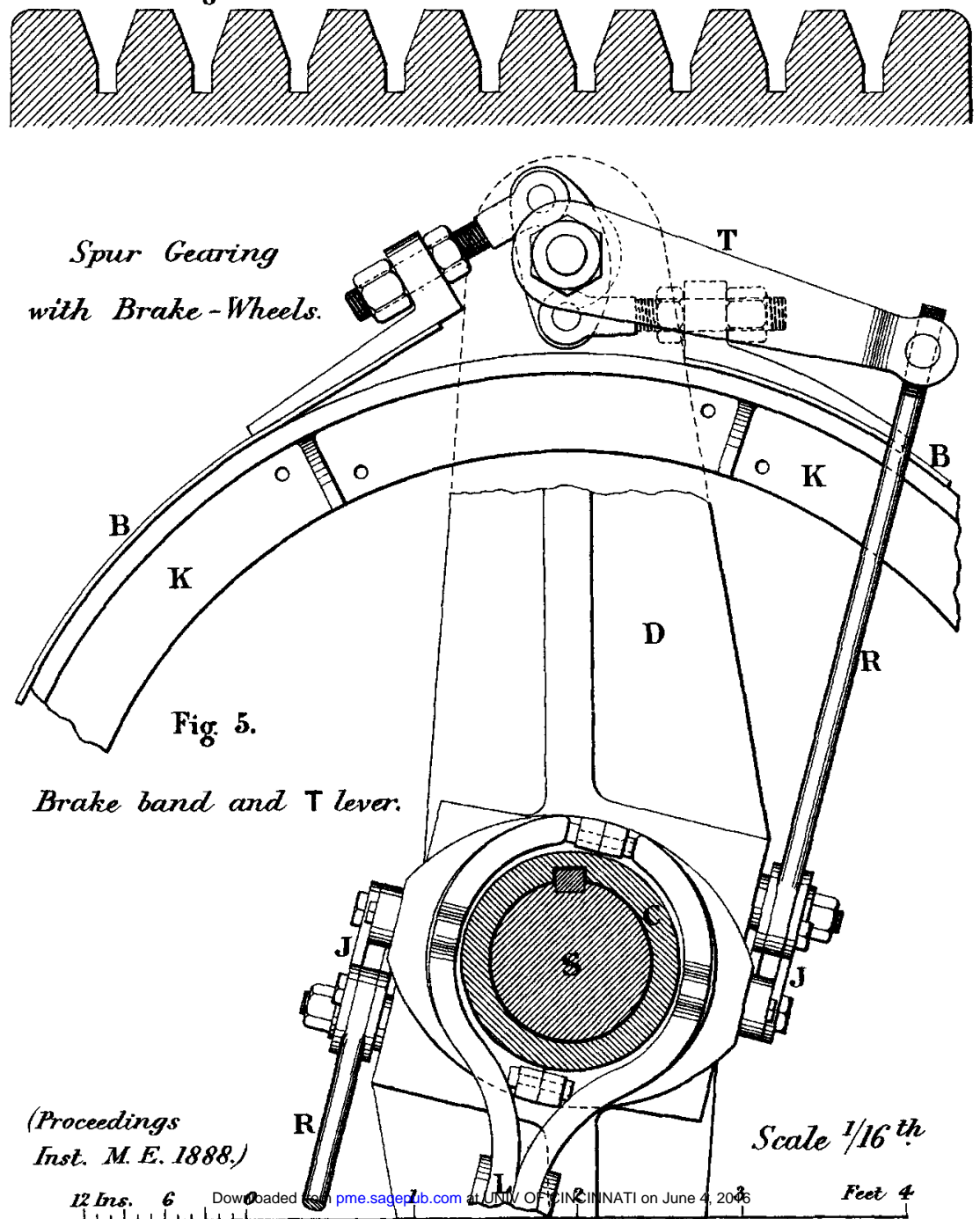


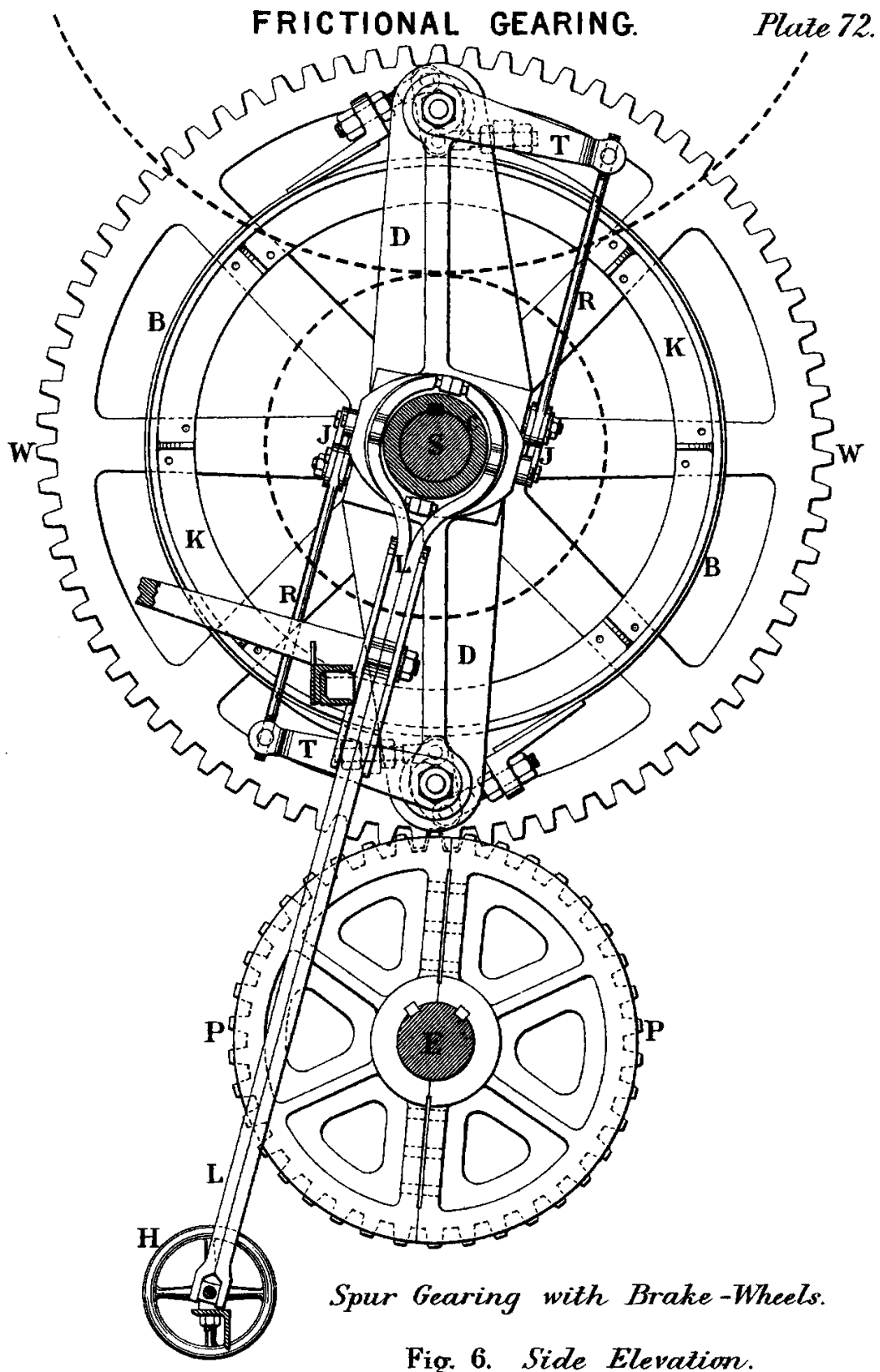

Fig. 6. Side Elevation.

(Proceedings Inst. M.E. 1888.)

Scale $1 / 32^{\text {nd }}$

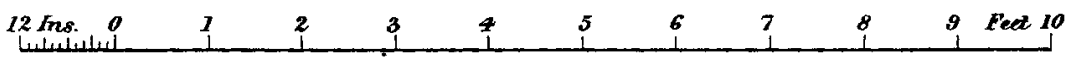




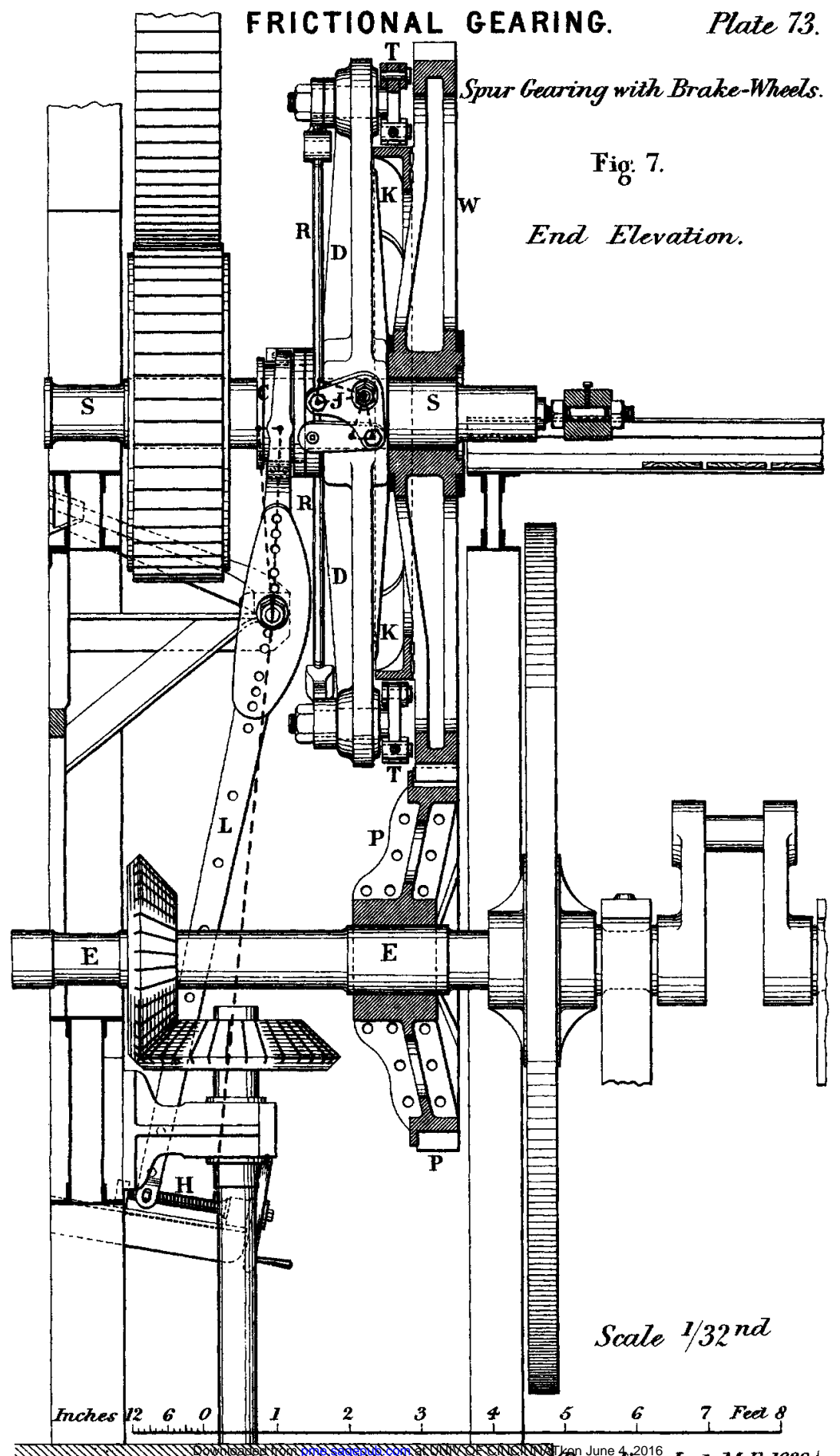

